\title{
RECONFIGURAÇÃO DO MERCADO DE TRABALHO: POLÍTICAS PÚBLICAS DE INCLUSÃO SOCIAL E PACTO SOCIAL.
}

\author{
Jane Gombar ${ }^{1}$ \\ Josiane Borghetti Antonelo ${ }^{1}$
}

\section{RESUMO}

Na medida em que se estuda as mutações do mundo do trabalho, verificamos que a sociedade está se mobilizando no sentido de encontrar fórmulas-alternativas, como resposta deste ramo jurídico (direito do trabalho) a atual fase do capitalismo, da globalização, da crise econômica e da revolução tecnológica do último século, que provocaram mudanças nas relações de trabalho, ensejando novas formas de organização de produção e a discussão de conceitos até a então firmemente arraigados na doutrina e jurisprudência. $O$ recente debate cientifico em tema de trabalho se caracteriza por um consenso sempre mais difuso segundo o qual o direito do trabalho deveria ser reformulado como um direito ao mercado de trabalho que reformula constantemente seus paradigmas em razão do mercado econômico e político advindos de diversas matizes, especialmente da globalização internacional, que seria a nova revolução, sutil e contundente, modificadora e complexa, mudando os tratamentos sociais e espaços, interesses e equações econômicas, os processos e resultados produtivos, valores e conceitos culturais, vontades e valores políticos, pessoas e instituições. O presente artigo é especialmente direcionado para a importância do dialogo social, através dos pactos sociais, a partir "Libro Verde", adotados na União Européia, que objetivam uma discussão entre vários atores sociais sobre a temática trabalho, inclusão social, mercado e flexibilização.

Palavras-chave: Diálogo Social. Flexibilização. Mercado de Trabalho. Mutações.

\section{MERCADO DE TRABALHO: ASPECTOS GERAIS}

O recente debate cientifico em tema de trabalho se caracteriza por um consenso sempre mais difuso segundo o qual o direito do trabalho deveria ser reformulado como um direito ao mercado de trabalho, ou segundo as palavras de Richard Mitchell "dovebre essere riformulata o riconfigurata come diritto del mercato del lavoro"?

Trabalho este que reformula constante seus paradigmas em razão do mercado econômico e político advindos de diversas matizes, especialmente da globalização internacional, que seria a nova revolução, sutil e contundente, modificadora e complexa, mudando os tratamentos sociais e espaços, interesses e equações econômicas, os processos e resultados produtivos, valores e conceitos culturais, vontades e valores políticos, pessoas e instituições. Habermas acredita que a conseqüência disto é que: 


\begin{abstract}
Hoje, a dominação está submetida a uma racionalidade tecnológica que se perpetua e se estende, não apenas através da tecnologia, mas enquanto tecnologia, e esta garante a formidável legitimação do poder político em expansão, que absorve todas as esferas da cultura. Nesse universo, a tecnologia provê também a formidável racionalização da não-liberdade do homem e demonstra a impossibilidade técnica de ser ele autônomo e de determinar a própria vida. Isso porque essa liberdade aparece, não como irracional ou política, mas antes, como uma submissão ao aparato técnico que amplia as comodidades da vida e aumenta a produtividade do trabalho. ${ }^{3}$
\end{abstract}

Se o mundo assiste, na atualidade, a realidade de Estados frágeis (ou pelo menos fragilizados), mesmo quando nos referimos a alguns tipos tidos como potencias se os próprios blocos comunitários ou sistemas integrados, até hoje, não conseguiram formar para si e, menos ainda, dar aos países que os compõem, a força que se exigiria, institucionalmente, para cumprir e fazer cumprir, satisfatoriamente regras disciplinadas de convivência internacional, compreende-se que Stanley Hoffmann diga que : "vivemos em um mundo em que uma sociedade de Estados desiguais, e em ocasiões virtuais, se sobrepõe (?) a uma sociedade global formada por frágeis instituições públicas e sociedades civis subdesenvolvidas"”

Vale o alerta sobre a incapacidade objetiva de poder também dos organismos internacionais (ONU, entre outros). A análise detalhada mostra que, mais do que nunca, passa-se por um período acelerado, e aparentemente "sem destino", de mudanças: na estrutura familiar, nas relações interpessoais, nas hierarquias funcionais, no plano institucional, na área produtivo-laboral, no risco do empreender, nos limites (quais?) espaciais do agir, nos valores civilizatórios e culturais (da ética 'a religião) e na missão (existirá?) do próprio Homem: de onde, para onde e por quê?

Com isso, tem-se uma crise valorativa que, a partir de Max Weber, poder-se-ia denominar como tempo de desencantamento, ou, aproveitando a expressão de Robert Heilbroner, chamá-la de mal-estar civilizacional.

Vive-se o inquietante paradoxo gerado, de um lado, pelo reconhecimento da valia insuperável, decorrente dos avanços tecnológicos nos diversos compartimentos científicos e seus múltiplos benefícios (saúde, sabedoria, produtividade etc) e, simultaneamente, de outro, também os malefícios de sua utilização descontrolada ou desvirtuada (as drogas, o desemprego pela automação etc).

É como se a humanidade estivesse vivenciando, uma vez mais, de forma perigosa e aguda, a condição de ser moderno e isto quisesse dizer, na lição de Berman Marshall, o encontrar-se

[...] em um ambiente que promete aventura, poder, alegria, crescimento, autotransformação, transformação das coisas em redor - mas, ao mesmo tempo, ameaça destruir tudo o que temos, tudo o que sabemos, tudo o que somos. 
Tal manifestação, que leva ao catastrofismo, atenua-se pela própria capacidade tradicional da sociedade de proteger-se de males maiores. Há riscos (grandes) e incertezas (muitas), mas há, também, uma consciência de que eles existem e de que elas precisam ser enfrentadas. Não há dúvida de que, não poupando nem mesmo as grandes potências, a situação periclitante atinge, prioritariamente, países periféricos porque expostos aos mesmos perigos dos maiores, sem, no entanto, terem tido, como estes, o desfrute pleno dos benefícios da mudança e da capa, parcialmente protetiva, que disso decorre.

Deve-se destacar que um relevante grupo de doutrinadores considera a falta, tanto de poder explicativo como de poder normativo, no paradigma dominante no direito do trabalho na segunda metade do século $\mathrm{XX}$ diante da práxis atual do mercado de trabalho(tanto interno quanto esterno da empresa), considerando-se as mais recentes teorias econômicas sobre mercado de trabalho e sobre a sua instituição, observando-se o mutamento do contesto social complexamente considerado. ${ }^{6}$

A orientação no sentido de um estranhamento em direção a uma problemática clássica do direito ao trabalho não deve ser superestimada. Um das mais importantes desta é a idéia neo-liberal:

\begin{abstract}
Uno dei più importanti di questi è stata la prepotente ascesa delle idee neoliberaliste, tanto in economia quanto nella scienza della regolazione giuridica. La preferenza che economia neoclássica e ideea neoliberiste mostrano per il libero mercato e le liberta individuali rispetto ai mercati regolamentati e all'aproccio di matrice colletivista ha dominato il dibattio político di tutti i Paese sviluppati e industrializzati nelle ultime due decadi, lanciando uma sfida ai fondamenti intellettuali delle relazione industriali $\mathrm{e}$ dei sistemi di dirrito del lavoro in ocidente. ${ }^{7}$
\end{abstract}

Ao lado desses fatores preementes, registra-se o desenvolvimento no contesto político e social: mudanças nas estruturas das empresas e nas suas práticas comerciais (aqui se pensa no fenômeno do outsourcing, o trabalho de aluguel, de franchising, cadeias de suprimentos, modelos de produção transnacional, privatizações, cortes nas ocupações); mudanças na composição da população e da força de trabalho(aqui se pensa nas mudanças na composição familiar, no aumento da força feminina no mercado, na carência de mão de obra qualificada, no envelhecimento da população e na discriminação etária); nas mutações do modelo organizativo de trabalho(aqui se pensa no trabalho part-time, trabalho temporário, intermitente, a domicilio, o teletrabalho) que nos levam a um processo para repensarmos as respostas a estes novos paradigmas e, conseqüentemente, suas evoluções no sistema jurídico.

No avizinhar-se a este estudo é absolutamente essencial manter um olhar entre o passado e futuro, adotando uma prospectiva di questionamentos com o fim de desenvolver uma compreensão de todo o período de mutação relevante que guardou a elaboração jurídica do mundo do trabalho. Como diz Krishan Kumar:

A história se desenvolve em etapas, tanto contínuas como descontínuas. As prevalência do pós-modernismo hoje em dia, portanto, não sugerem que 


\begin{abstract}
idéias ou instituições do passado deixem de moldar o presente. $O$ modernismo e o pós-modernismo não são separados por uma Cortina de Ferro ou uma Muralha da China, isto porque a história é um palimpsesto e a cultura é permeável ao tempo passado, ao tempo presente, ao tempo futuro. Desconfio que todos nós somos, ao mesmo tempo, um pouco de vitorianos, modernos e pós-modernos. Isso significa que um "período" deve ser visto simultaneamente em termos de continuidade e descontinuidade, sendo as duas perspectivas complementares e parciais. ${ }^{8}$
\end{abstract}

Adotar um referimento temporal amplo evidencia importante perfil nos estudos sobre o tema na regulação do mercado de trabalho através dos diversos séculos, onde se encontra a tendência "diffusa a considerare gli slittamenti nelle politiche del lavoro come indesiribili allontamenti da sistemi o modeli dati o inevitabile"9.

Movendo-se a partir da teoria dos sistemas de Luhmann, nota-se que o direito requer uma dúplice perspectiva de indagação: uma compreensão partindo-se internamente do modelo e dos métodos de interpretação jurídica (a elaboração jurídica que move das decisões presas ao direito) e uma compreensão do fenômeno jurídico a luz do contesto mais geral das relações sociais (a analise do direito como influencia no contesto social e como tal contesto o influenciou)

Talvez com esta já tão nova metodologia de analise seja possível perseguir e criar um novo mapeamento a fim de propor soluções idôneas sob o ponto de vista social e econômico.

\title{
2 O DESEMPENHO DO MERCADO DE TRABALHO DIANTE DO PROCESSO DE RENOVAÇÃO CONCEITUAL: O PADRÃO DA FLEXIBILIZAÇÃO
}

O comportamento dos mercados de trabalho é de grande importância no desempenho da economia. Ele afeta o volume de empregos criados, as taxas de desemprego e de aumento de produtividade, o grau de conflito entre agentes, 0 montante de investimentos e muitas outras variáveis importantes. Na medida em que se estuda as mutações do mundo do trabalho, verificamos que a sociedade está se mobilizando no sentido de encontrar fórmulas-alternativas, como resposta deste ramo jurídico (direito do trabalho) a atual fase do capitalismo, à globalização ${ }^{10}$, à crise econômica e a revolução tecnológica do último século, que provocaram mudanças nas relações de trabalho, ensejando novas formas de organização de produção e a discussão de conceitos até a então firmemente arraigados na doutrina e jurisprudência.

Todavia, a complexidade dos fenômenos que ocorrem no mundo do trabalho e das empresas é extremamente grande para querer apreendê-la em sua totalidade e as pesquisas que se esforçam para explicá-los são demasiadamente variadas para termos a audácia de inventariá-las. De uma maneira mais modesta decidimos, então, apresentar um fio condutor através da flexibilidade que nos permita analisar um certo número de corrente de pesquisas e modelos a fim de propor uma interpretação das novas propostas que a sociedade encontra em matéria de ocupação. 
Dentre as inúmeras propostas que a doutrina apresenta ${ }^{11}$ como um novo modelo de trabalho, optamos em analisá-las sob o enfoque acima referido face aos cambiamentos e as políticas existentes no sentido de multiplicação das formas de trabalho e modelos de contratos de trabalho existentes "per la migliore funzionalità dei servizi all'impiego e per lo sviluppo della capacita dei soggeti privati di svolgere um ruolo attivo in questo ambito." 12

A comparação, ao menos entre países que apresentam um apreciável grau de afinidade na tradição jurídica e na cultura social, tais como o Brasil e Itália, possibilita uma aproximação bastante frutífera ao estudo do tema flexibilidade, eis que em ambos os países o debate é insistente e acirrado, pois "da um paio di decenni la flessibilità há conquistato um ruolo di primo piano nella letteratura manageriale e organizzativa come carrateristica che distingue le imprese eccelenti” ${ }^{13}$.

Vastíssima é a literartura que "si è sviluppata in Europa e nel América sul lavoro e sul suo ruolo sociale nella società industriale" ${ }^{\text {14 }}$.

Verificando-se a legislação existente sobre o tema, se pode afirmar que o Brasil e Itália seguiram, na política de flexibilização, trajetórias distintas, mas convergentes em alguns pontos. O ponto de partida é relativamente similar. Nos dois países, a flexibilização é apresentada como um processo de modernização da legislação trabalhista, ligado a um eixo sobre a passagem de um garantismo rígido e eminentemente individual a um garantismo dinâmico e eminentemente coletivo, entre um quadro de referimento dos acordos políticos entre governos, envolvendo sindicatos e a sociedade.

A Itália introduziu uma pequena regulamentação de mercado de trabalho no ano de 1.970, o estatuto dos trabalhadores, e a completou nos anos sucessivos, ou seja: no período mais turbulento no qual se observa a primeira crise do petróleo(1973) e a conseqüente onda de infração e revisão do processo produtivo.

Nesse sentido, Innocenzo Cipolletta esclarece que:

Di fatto l'Italia, sull'esempio di quanto già fatto da altri paese
europei,introdusse regole piú rigide sul mercato Del lavoro e sullo stato
sociale(oltre lo Statuto dei lavoratori, venne decisa l'abolizione delle gabbie
salariali, l'unificazione del punto di contingenza, l'introduzione della
contrattazione aziendale, II sistema universale per La previdenza e l'
assitenza sanitária, e altri provvedimenti che andarano a sovrapporsi a una
conflitualità aziendale fortemente accresciuta), in un período (gli anni'70) in
cui gli eventi avrebbero suggerito invece di introdurre maggiore flessibilità
per resistire ai diversi shock esterni ${ }^{15}$

Nesse aspecto verifica-se que, enquanto muitos países começaram a procurar e estudar formulas para superar a rigidez existente e encontrar formulas para favorecer o processo de adaptamento, a Itália se encontrava, pelo seu retardo, ao contrário da tendência de outros países, numa espécie de choque de oferta, sem que houvesse uma suficiente flexibilidade, que "solo con la metà degli anni'80 che si iniziò a immaginare le prime misure di flessibilità"16. 
Tem-se, então, como início do resultado dessas medidas a introdução do contrato di formazione-lavoro, cujo objetivo era reduzir o custo do trabalho dos jovens "assunti attraverso um inquadramento piú basso e una riduzione degli oneri sociale"17 que servia como compensação, por parte da empresa, pelas despesas de suas formações.

A partir de então, sucessivamente foram introduzidas políticas de flexibilização no mercado de trabalho, especialmente a partir dos anos 90 , quando a Itália decide aderir a moeda européia e de renunciar, portanto, ao desvalorizamento competitivo. Esta decisão força as empresas a recuperarem seus custos internos daquela flexibilidade que até então estava assegurada sobre preços externos da empresa, graças à continua desvalorização da lira, provocando a necessidade de um novo modelo contratual.

\section{COMPLEXIDADE: A PARTICIPAÇÃO DA SOCIEDADE NO DEBATE SOBRE MERCADO DE TRABALHO ATRAVÉS DOS PACTOS SOCIAIS}

Ao contrário do Brasil, que não possui um diálogo social ao nível europeu e italiano, nota-se que boa parte da flexibilização na Europa, em especial na Itália, deu-se e pela participação ativa de sindicatos representativos das classes, mútua cooperação e pelos pactos sociais, que para José Augusto Rodrigues Pinto é:

[...] um acordo de vontades, estabelecido entre o estado e as representações de trabalhadores e empresas, para determinar um ampla política econômica de equilíbrio de produção e do emprego, que sirva de base para a normatização coletiva das condições de trabalho pelas respectivas categorias. ${ }^{18}$

A leitura das recomendações européias ilustram claramente este fenômeno. Desde a publicação do "Libro Bianco" tudo deve ser flexível nos mercados de trabalho europeus: os trabalhadores, as formações, os horários, os tempos de trabalho,, os salários e os sistemas de produção que os mantém ocupados, facilitando os recursos a formas de trabalho menos custosas, tais como o trabalho temporário, trabalho independente, tempo parcial, trabalho em domicílio, estágios ou aprendizagem de jovens, entre outros.

A análise sistemática do seu conteúdo indica que

É indispensável que, em todos os níveis, os parceiros sociais sejam estimulados a desenvolver modelos de relação de trabalho a fim de melhorar a flexibilidade e adaptar-se às evoluções das estruturas de produção, tanto nas grandes como nas pequenas empresas ${ }^{19}[\ldots] \mathrm{O}$ aumento da flexibilidade deverá refletir nas regulamentações e nos sistemas de negociação coletiva, facilitando uma maior adaptação às características dos mercados locais e das empresas. ${ }^{20}$ 
Dentre as prioridades e as principais diretrizes no encontro sobre emprego em Luxemburgo, justificadas em três capítulos dedicados ao emprego, destacamos:

1. Melhorar a capacidade de inserção profissional: diretriz que retoma as idéias relativas a formação, à passagem de políticas passivas para políticas ativas;

2. Desenvolver o espírito de empreendimento, simplificando as regulamentações, aliviando os encargos sociais, desenvolvendo as iniciativas locais;

3. Estimular a capacidade de adaptação das empresas e seus trabalhadores, modernizando as organizações e as formas de trabalho: maleabilidade e segurança, redução do tempo de trabalho, anualização do tempo de trabalho, redução das horas extras, desenvolvimento do trabalho em tempo parcial, formação ao longo de toda a vida e interrupções de carreira(os trabalhadores beneficiados por contratos desse tipo deveriam beneficiar-se ao mesmo tempo de uma segurança suficiente e de um melhor status profissional, compatível com as necessidades das empresas);

4. Reforçar as políticas de igualdade de oportunidades: particularmente através da promoção de interrupções de carreira e do trabalho em tempo parcial, que permite conciliar vida profissional e vida familiar.

Nota-se que as diretrizes adotadas, discutidas amplamente com a sociedade, levam em questão as relações entre mercado de trabalho e evolução das sociedades industriais e, notadamente, as mutações no mundo do trabalho e sua ligação intrínsica com a flexibilização.

\section{A ESTRUTURA DE BASE: A REFORMA DO MERCADO DECORRENTE DA FLEXIBILIZAÇÃO}

A expansão de tais objetivos é destacada pelas medidas adotadas no País pela "Legge Biaggi", que compõe uma das facetas na nova política da flexibilização da legislação trabalhista, através do projeto de lei de reforma do mercado de trabalho aprovado pelo Parlamento em 05 de fevereiro de 2003(Lei 30, de 14 de fevereiro de 2003), Decreto Legislativo n‥ 276, de 10 de setembro de 2003(cujo texto passou a vigorar em 24 de outubro de 2003), em matéria de ocupação e de mercado de trabalho e a Lei 30, de 14 de fevereiro de 2003 .

$\mathrm{Na}$ exegese da doutrina:

Sulla base del lavoro di Marco Biaggi, anche lui tragicamente ucciso della Brigate rosse, si redasse uma legge che aveva come obiettivo quello di regolamentare la flessibilitá del mercato del lavoro, introducendo nuove forme di prestazione del lavoro dipendente (jobsharing, staff leasing, ecc...) e ponesse fine all' uso indiscriminato del lavoro a termine, ricompresso nelle formule del lavoro a progetto, dove II progetto fosse bem definito, sai come obiettivi che come termine di inizio e di fine. ${ }^{21}$ 
Naturalmente, como resultado dessa situação, importante é a transcrição do relato de Tiziano Treu ao referir que "introducono cambiamenti diffusi nelle regole del rapporto e del mercato del lavoro in Itália: cambiamenti riguardanti la gran parte degli istituti e delle prassi rilevanti in questa matéria"22.

É nesse quadro de flexibilização que

\begin{abstract}
La rivoluzione del collocamento sattuata com il d.lgs. 10 settembre $2003 \mathrm{n}$. 276(artt.3-19) è la misura struturale dalla quale si aspettano i maggiori risultati in tema di occupazione: la trasformazione dei vecchi uffici di collocamento nei nuovi centri per l'impiego, l'ingresso nel mercato del lavoro di nuovi operatori, il decentramento delle competenze, è auspicabile che possano cntribuire al più presto al passagio da uma cultura dell'assistenza ad uma cultura della promozione, rendendo più dinâmico e competitivo il sistema. ${ }^{23}$
\end{abstract}

De modo geral, este processo de reestruturação é uma reforma inovativa que objetiva o crescimento da ocupação, não tendo o presente trabalho o objetivo de analisar seus aspectos positivos ou negativos. Entre as principais novidades da lei deve-se destacar, no artigo 4ํㅜ , papel atribuído as agências de emprego.

No que se refere à administração do trabalho, no artigo 20 está previsto que "o contrato de administração do trabalho pode ser por tempo determinado ou indeterminado".

Quanto ao trabalho intermitente, o artigo 32 aborda que "o contrato intermitente é aquele por meio do qual um trabalhador é posto à disposição de um empregador que pode utilizar sua prestação de trabalho nos limites previstos no artigo 34 [...]. O contrato de trabalho intermitente pode ser estipulado também por tempo determinado". Acrescenta-se ainda a figura do trabalho dividido (artigo 41), ou seja: "um contrato especial de trabalho pelo qual os trabalhadores assumem a execução de uma idêntica obrigação de trabalho"24.

No artigo 47 e seguintes, temos a figura da aprendizagem e as regras quanto ao período de aprendizagem, que é estruturado durante a fase de formação e do trabalho alternativo, prevendo facilidades para jovens na faixa etária entre 16 e 24 anos, observando-se as exceções e o período de formação.

Já no artigo 54 há o contrato de inserção, que determina a sua aplicação a "um contrato de trabalho dirigido ao ingresso e reingresso no mercado de trabalho de uma série de categorias, por intermédio de um plano individual de adaptação das capacidades profissionais do trabalhador em um contexto de trabalho determinado".

Destaca-se ainda o artigo 69 que descreve as relações de colaboração coordenada e continuada, afirmando que se "forem estabelecidas sem a indicação de um plano específico de um programa de trabalho ou de uma fase do mesmo,

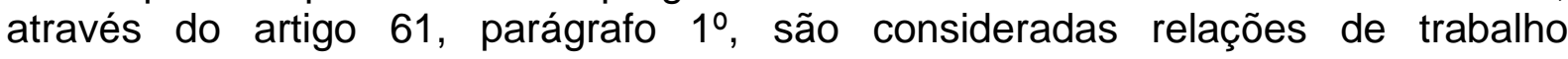
subordinado por tempo indeterminado a partir da data da constituição da relação". Trata-se de um contrato firmado por meio de escritura privada, que estabelece uma relação de trabalho subcontratado, no qual o trabalhador, do ponto de vista legal- 
regulamentar, oferece sua prestação de forma continuada e coordenada e faz seu trabalho de forma completamente individual, não tendo de se submeter às diretivas de nenhum contrato coletivo.

Por outro lado, com o contrato de empreitada, as empresas podem preparar um contrato de fornecimento de força de trabalho com agencias especializadas que as atendem em tempo real e apenas em períodos solicitados. Geralmente trata-se de um contrato por tempo determinado que oferece um trabalho limitado no tempo, para qualificações as vezes muito elevadas, o que configura e institucionaliza uma forma de precarização da vida por meio da vigência do trabalho atípico.

Precisamos registrar que o trabalho de tempo integral e indeterminado é apenas um entre os vários tipos de empregos existentes. Entre as denominadas formas atípicas, existe, ainda, a prestação do serviço ocasional, ou seja, uma forma de contrato em que o trabalhador executa concomitantemente um serviço de natureza autônoma e ou liberal, sem nenhum vínculo empregatício.

Também foi previsto o josharing, trabalho compartilhado ou trabalho de parelha ou trabalho dividido, que institui um contrato de trabalho subcontratado em que um trabalho é executado por dois trabalhadores que compartilham o trabalho, horário e os turnos.

Com a introdução de tais medida em matéria de trabalho, verificamos que está presente uma grande fragmentação dos papéis de trabalho produtivo, pois a disciplina rígida foi substituída pela flexibilização, indo ao encontro das propostas adotadas no mercado comum europeu .

\section{ANÁLISE DO LIBRO VERDE: A PROPOSTA DA MODERNIZAÇÃO DO DIREITO DO TRABALHO}

Neste contexto, a publicação do livro verde ${ }^{25}$, através da commissione delle comunitá europee, Bruxelles, em 22 de novembro de 2006, intitulada "Modernizzare II diritto Del lavoro per rispondere alle sfide del XXI secolo", objetivou lançar um debate publico na União Européia que tinha por fim uma reflexão sobre o modo de se obter um crescimento sustentável "con più posti di lavoro di migliore qualità" ${ }^{26}$, já que a modernização do direito do trabalho constitui um elemento fundamental para garantir a capacidade de adaptação dos trabalhadores e das empresas a fim "di prumuovere una forza di lavoro preparata, formata e flessibile e mercati di lavoro in grado di rispondere talle sfide generate dal dúplice impatto della mondializzazione e dell' invecchiamento demografico in crescita e l' occupazione"27.

Buscando entender o panorama de nossa contemporaneidade, suas causas e efeitos, submerge um estudo relacionado ao Consiglio europeo, observando-se que se pode alcançar um mercado de trabalho com duas velocidades: uma sendo o trabalhador integrado com um posto de trabalho permanente e, em outra, aqueles que se encontram excluídos, em particular os desocupados, as pessoas afastadas do mercado de trabalho e aquelas que se encontram em situações de trabalho precário e informal, sendo que estes últimos ocupam uma zona cinza, cujo direitos fundamentais de trabalho ou da prestação social são praticamente inexistentes, 
gerando uma situação de insegurança. Na análise, o recurso às formas alternativas de ocupação seria adequar os contratos de trabalho de modo a facilitar uma maior flexibilidade, seja para o trabalhador, seja para a empresa, adaptando-se a legislação do trabalho para promover a flexibilidade em conjunto a segurança da ocupação e redução da segmentação do mercado de trabalho, aliada ao diálogo social.

Há um indicativo no Libro Verde que aborda a situação e desenvolvimento do direito do trabalho nell' Uninone Europea, analisado sob dois aspectos: $O$ primeiro deles verifica o propósito inicial do direito do trabalho que era de remediar a desigualdade econômica e social inerente as relações de trabalho, baseado no modelo tradicional, preocupando-se em definir a situação da ocupação como o principal fator em torno do qual se desenvolvem vários direitos “i) dell'ipotesi di um'occupazione permanente a tempo pieno; ii) dell'ipotesi che i rapporti di lavoro sono disciplinati dal diritto del lavoro, intorno al contratto di lavoro; iii) dell'ipotesi che um datore di lavoro único è responsabile del rispetto degli obblighi che incombono ai datori di lavoro" 28 . O segundo, a rapidez do progresso tecnológico, intensificado pela concorrência coligada a globalização, a evolução das exigências dos consumidores, o crescimento no setor de serviços, acentuando a necessidade de aumentar a flexibilização

\begin{abstract}
l'emergere della gestione "just-in-time", la tendenza della imprese a rivedere la loro política d'investimento a più breve termine, la diffusione delle tecnologie dell'informazione e della comunicazione, oltre alle evoluzioni della domanda sempre piú frequenti, hanno spinto le imprese a organizzarsi in modo più flessibile. Tutto ciò riguarda l' evoluizione dell'organizzazione e dell'orario di lavoro, i salari e II numero di dipendenti nelle varie fasi del ciclo produtivo. ${ }^{29}$
\end{abstract}

Estes fatores, segundo o Libro Verde, criaram uma necessidade de um aumento da diversificação contratual, já que os modelos tradicionais de contratos de trabalho não era adequados para responderem as novas exigências desse novo mercado, tais como " $\mathrm{i}$ contratti a tempo determinati, i contratti a tempo parziali, $\mathrm{i}$ contratti di lavoro intermittente, i contratti zero ore, i contratti proposti ai lavoratori independenti, ecc..."30, que constituem, atualmente, parte integrante das características do mercado de trabalho europeu.

E preciso compreender que esse pacto social estabelece uma série de diretrizes enfocando novas formas de trabalho, flexíveis, através de um amplo diálogo social em matéria de ocupação do mercado de trabalho europeu, que propõe um fator de promoção e ocupação e " di stimulare la discussione sulla questione di sapere se um quadro regolamentare più reattivo sia necessario per raforzare la capacià dei lavoratore ad antecipare e gestire i cambiamenti, independentemente della tipologia dei contratti - a durata indeterminata o a durata determinata atípica"31.

Nesse particular destaca Giovanni Garafolo:

II libro verde" modernizzare II diritto del lavoro per rispondere alle sfide del XXI secolo" è un ottima espressione della prima delle REVISTA DO DIREITO UNISC, SANTA CRUZ DO SUL № 33 | P. 54-67 | JAN-JUN 2010 
tendenza ora descrite e, come altre manifestazioni della stessa, assolutizza alcuni aspetti veri della dinâmica sociale e ne ignora del tutto altri. ${ }^{32}$

Tem-se, assim, a extração da idéia da preocupação social existente por parte da comunidade européia e, conseqüentemente, da Italiana no sentido da inclusão social dos trabalhadores através da apresentação de novas perspectivas de trabalho, num mundo cada vez mais flexível, destacando-se dentre das inúmeras propostas como "modelli di impresa e rapporti di lavoro nell'era della flessibilità" ${ }^{33}$, o contrato a termine pois

\begin{abstract}
Il processo di regolazione sociale dei contratti com um termine finale di durata nell'ordinamento italiano si inserisce nel quadro sopra descrito, rispechiando nel proprio codice genetico l'assunto secondo cui la regolazione di tale matéria è stata, ed è tutti oggi, ispirata a um compromesso fra l'interessa datoriale a utilizzare i contratti a termine per rendere più efficiente l'impresa o, più di recente, l'interesse alla difusione di dette forme di flessibilità in chiave occupazionale, da uma parte, e l'interesse alla sicurezza e alla stabilitá lavorativa dei prestatori." ${ }^{\text {"3 }}$
\end{abstract}

A contribuição para a coesão social, com um modelo de welfare que se preocupe com os valores sociais e princípios que o inspiram, fazem parte da constituição social do País e da sua comunidade, não só na relação capital e trabalho, mas a um referimento mais geral condicionado a idéia de que a solidariedade integrativa, conduzida pelo debate social, pode ser um caminho de superação de conflitos e de construção de um redesenhamento social.

\title{
LABOR MARKET RECONFIGURATION: SOCIAL INCLUSION PUBLIC POLICIES LINKED TO SOCIAL PACT
}

\section{ABSTRACT}

Insofar that studies the mutations of labor world, we check that society is moving towards finding alternative formulas, as a response of this branch of law (labor law) the current phase of capitalism, globalization, economic crisis and the technological revolution of the last century, which led to changes in labor relations, occasioning new forms of organizing production and discussion of concepts until then firmly rooted in the doctrine and jurisprudence. The recent scientific debate of work theme is characterized by a consensus ever more pervasive, according to which labor law should be recast as a right to the job market that constantly recasts their paradigms in reason of the economic and political market from various shades, especially the international globalization, which would be the new revolution, subtle and blunt, modifier and complex, changing social and spaces treatments, interests and economic equations, processes, and productive results, values and cultural concepts, desires and political values, people and institutions. The present article is especially directed to the importance of social dialogue, through social pacts, from "Libro Verde" adopted in the European Union, which aim a discussion between various social actors about the thematic of labor, social inclusion, market and 
flexibilization.

Keywords: Flexibilization. Larbor Market. Mutations. Social Dialogue.

\section{NOTAS}

1 Doutora em Direito pela Scuola Dottorale in Diritto ed Economia "Tullio Ascarelli", sezione Diritto Privato per'IEuropa- XXII ciclo - Università Degli Studi Roma Tre - Roma, Itália. Professora de direito do trabalho e processo do trabalho da Universidade de Santa Cruz do Sul - UNISC e UNIVATES - Lajeado. Professora convidada de Cursos de pós-graduação de várias IES. Coordenadora do curso de pós-graduação em direito do trabalho, processo do trabalho e direito previdenciário da UNISC. Assessora jurídica trabalhista do Sindicato do Comércio Varejista do Vale do Rio Pardo-RS desde 1989. E-mail: janegombar@unisc.br. Endereço: Sindicato do Comércio Varejista de Santa Cruz do Sul - Rua Ernesto Alves, 714 - Centro - CEP 96810-060 Santa Cruz do Sul-RS, Brasil.

1 Advogada. Mestranda em Direito na UNISC - Universidade de Santa Cruz do Sul e integrante do Grupo de Pesquisas "Direito, Cidadania e Políticas Públicas" coordenado pela Profa. Pós-Doutora Marli Marlene M. da Costa. E-mail: josianebantonelo@gmail.com. Endereço: Nunes Antonelo Advogados Associados - Praça Silvestre Corrêa, 71 - Centro - 96610-000 - Encruzilhada do Sul, RS - Brasil.

2 MITCHELL, Richard. II diritto del mercato del lavoro tra politiche di workfare e procedure di certificazione. Diritto delle relazione industriali. Giufré Editore: Milano, numero 2, ano XVIII, pp. 293-310, 2008.

3 HABERMAS, Jurgen. Técnicas e ciência enquanto ideologia. In: BENJAMIM, Walter (et. Al.) Textos escolhidos. 1 ed. São Paulo: Abril cultural, 1975, p. 305.

4 HOFMANN, Stanley. Choque de Globalizações. Análise de economia regional para homens de negócios. Porto Alegre, Helio Gama, 320/321, 2002, pág. 8

5 MARSHALL, Berman. Tudo que é solido desmancha no ar: a aventura da modernidade. São Paulo: Companhia da Letras 85, 1987, p. 15.

6 Nesse sentido: MITCHELL, Richard. Op. cit., p. 294.

7 MITCHELL, Richard. Op. cit., p. 294.

8 KUMAR, Krishan. Da sociedade pós-industrial à pós-moderna: novas teorias sobre o mundo contemporâneo. Tradução de Ruy Jungmann. Rio de Janeiro: Jorge Zahar, 1997, p.155.

9 MITCHELL, Richard. Op. cit., p. 297.

10 La globalizzazione intesa come despazializzazione del sociale schuide uma nuova cornice analitica in grado di indicare nuove opzioni strategiche. BECK, ULRICH. II lavoro nell'epoca della fine del lavoro: tramonto delle sicurezze e nuovo impegno civile. Traduzioni di Hellmut Riedeger. Torino: Enaudi,2000, p. 46.

11 De modo sintético podemos dizer, tomando alguns d e seus mais expressivos formuladores que Jeremy Rifkin em sua obra o fim dos empregos vislumbra a possibilidade de trabalho sob o viés do terceiro setor, enquanto que Domenico de Masi relata a oportunidade de trabalho através do ócio e das novas formulas por ela cridas.Ver: RIFKIN, Jeremy. O fim dos empregos: o declínio inevitável dos níveis de emprego e a redução da força global de trabalho. Tradução de Ruth Gabriela Bahr. São Paulo: Makron Books, 1995; DE MASI, Domenico. O futuro do trabalho: fadiga e ócio na sociedade pós-industrial. Tradução de Yadir A. Figueiredo. Rio de Janeiro/Brasília: José Olympio/UNB, 2000,__. . O ócio criativo: Tradução de Léa Manzi. Rio de Janeiro: Sextante, 2000, _. (Org.). A sociedade pós-industrial. Tradução de Anna Maria Capovilla. 3. ed. São Paulo: SENAC, 2000. , entre outros autores mais expressivos

12 TREU, Tiziano.Riforma Biagi e nuove regole del mercato del lavoro. In. FERRARO, GIUSEPE(a cura de) Sviluppo e occupazione nel mercato globale:stravolgimento economici, competizione dei sistemi locali, metamorfosi del lavoro. Milano: A. Guiffrè Editore S.p.A, 2004, pp. 155-199, p. 158. SEMENZA, Renata. Le trasformazione del lavoro: flessibilitá, disugualianze, responsabilità dell'impresa. Roma: Carocci editore, 2004, p. 17. Id. Ibem, p. 17.

15 CIPOLLETTA, Inoccenzo. Mercato o mercati Del lavoro? In: ACOORNERO, Iris(et.al.).La legge Lei Biaggi: anatomia di una riforma.. Roma: Editori Ruiniti, 2006, p. 89-98, p. 90. 
RODRIGUES PINTO, José Augusto. Direito Sindical e Coletivo do Trabalho. São Paulo: LTr 1998, p.198. (9.ANCO, Luxemburgo, 1994, p.155.

Ibid, p. 145

CIPOLLETTA, Innocenzo. Mercato o mercati del lavoro? In: ACCORNERO, Aris (et. al.) La legge Biaggi: anatomia di uma riforma. Roma: Editori Riuniti, 2006, pp. 89-98, p. 94

(n) RERRARO, GIUSEPE(a cura de) Sviluppo e occupazione nel mercato globale:stravolgimento economici, competizione dei sistemi locali, metamorfosi del lavoro. Milano: A. Guiffrè Editore S.p.A, 2004, pp. 155-199, p. 155. CARBONE, Di Leonardo; CARBONE, Daniela. Organizzazione e disciplina del mercato del lavoro. In: FAVALLI, Giacinto; STANCHI, Andréa. La riforma Biaggi: comento al Decreto legislativo 10 settembre 2003, n. 276. Roma: Casa Editrice La Tribuna, 2003, pp. 19-44, p. 19 Ver: Decreto Legislativo $\mathrm{n}^{\circ}$. 276, de 10 de setembro de 2.003. Segundo a definição oficial encontrada no portal da União Européia, verifica-se que "i Libri verdi sono documenti di riflessione su un tema politico specifico pubblicati dalla Commissione. Sono prima di tutto documenti destinati a tutti coloro - sia organismi che privati - che partecipano al processo di consultazione e di dibattito". Disponível em :http://europa.eu/documentation/officialdocs/index it.htm. Acessado em 04 de maio de 2010.

Ib. Idem, p. 3

LIBRO VERDE, p. 5.

Id. Ibem, p. 5.

Id. Ibem, p. 8.

LIBRO VERDE, p. 10.

GARAFOLO, Mario Giovanni. Post-moderno e diritoo del lavoro: osservazioni sul libro verde "modernizare il diritto del lavoro". In Rivista giuridica del lavoro e della previdenza sociale. Anno LVIII- 2007, n.1, gennaio-marzo 2007. Roma: Ediesse, 2007, pp. 135-144, p. 135.

ZAPPALÀ, Lorenda. Tra diritto ed economia: obietivi e tecniche della regolazione sociale dei contratti de lavoro a termine. Rivista giuridica del diritto del lavoro, Roma:Edieese, anno LVII, n.1, gennaio-marzo-2006, p. 171-214, p.176.

Id ibem, p.173-174.

\section{REFERÊNCIAS}

BECK, ULRICH. II lavoro nell'epoca della fine del lavoro: tramonto delle sicurezze e nuovo impegno civile. Traduzioni di Hellmut Riedeger. Torino: Enaudi, 2000.

CARBONE, Leonardo; CARBONE, Daniela. Organizzazione e disciplina del mercato del lavoro. In: FAVALLI Giacinto; STANCHI, Andrea. La riforma Biagi: commento al Decreto Legislativo 10 settembre 2003, n. 276. Roma: Casa Editrice La Tribuna, 2003, pp. 19-44.

CIPOLLETTA, Inoccenzo. Mercato o mercati Del lavoro? In: ACOORNERO, Aris(Org.).La legge Lei Biaggi: anatomia di una riforma.. Roma: Editori Ruiniti, 2006, p. 89-98.

DE MASI, Domenico. O futuro do trabalho: fadiga e ócio na sociedade pósindustrial. Tradução de Yadir A. Figueiredo. Rio de Janeiro/Brasília: José Olympio/UNB, 2000.

. O ócio criativo: Tradução de Léa Manzi. Rio de Janeiro: Sextante, 2000.

. (Org.). A sociedade pós-industrial. Tradução de Anna Maria Capovilla. 3. ed. São Paulo: SENAC, 2000. 
GAROFALO, Mario Giovanni. Post-Moderno e diritto del lavoro. Osservazioni sul libro verde "modernizzare il diritto del lavoro". Rivista giuridica del lavoro e della previdenza sociale, Roma: Edieese, anno LXIII, vol. 48, fasc. 1, pp. 135-161, 2007.

ITALIA, Decreto Legislativo no. 276, de 10 de setembro de 2003.

KUMAR, Krishan. Da sociedade pós-industrial à pós-moderna: novas teorias sobre o mundo contemporâneo. Tradução de Ruy Jungmann. Rio de Janeiro: Jorge Zahar, 1997.

LIBRO BIANCO. Commissione della Comunità Europea, Lussemburgo, 1994.

LIBRO VERDE, Bruxelles, 2006.

MARESCA, Arturo. La staggione della flessibilià e l'ordinamento del lavoro: un primo bilancio. In: D'ANTONA, Massimo(a cura di). Politiche di flessibilità e mutamenti del diritto del lavoro. Edizione Cientifiche italiane: Napoli, 1990, pp. 89-117.

MIRANDA, Nicola. II nuovo contratto a termine nel lavoro "privato" e"pubblico". Padova: CEDAM, 2007.

MITCHELL, Richard. II diritto del mercato del lavoro tra politiche di workfare e procedure di certificazione. Diritto delle relazione industriali. Giufré Editore: Milano, numero 2, ano XVIII, pp. 293-310, 2008.

Portal da União Européia: Disponível em: http://europa.eu/documentation/officialdocs/index_it.htm, acessado em 04 de maio de 2010.

RIFKIN, Jeremy. O fim dos empregos: o declínio inevitável dos níveis de emprego e a redução da força global de trabalho. Tradução de Ruth Gabriela Bahr. São Paulo: Makron Books, 1995.

RODRIGUES PINTO, José Augusto. Direito Sindical e Coletivo do Trabalho. São Paulo: LTr 1998.

SEMENZA, Renata. Le trasformazione del lavoro: flessibilitá, disugualianze, responsabilità dell'impresa. Roma: Carocci editore, 2004.

TREU, Tiziano. Riforma Biagi e nuove regole del mercato del lavoro. In. FERRARO, GIUSEPE(a cura de) Sviluppo e occupazione nel mercato globale:stravolgimento economici, competizione dei sistemi locali, metamorfosi del lavoro. Milano: A. Guiffrè Editore S.p.A, 2004, pp. 155-199.

ZAPPALÀ, Loredana. Tra diritto ed economia: obbiettivi e tecniche della regolazione sociale dei contratti di lavoro a termine. Rivista Giuridica, Roma: Edieese, anno LVII, n. 1, pp. 171-214, gennaio-marzo 2006.

Recebido para publicação: 07/06/2010

Aceito para publicação: 23/12/2010 